\title{
Vitamin D supplementation. Is it the time to stop wasting money on vitamin D?
}

In recent years, vitamin D has received increased attention, as a number of studies have shown its link to the pathogenesis of various diseases. Apart from its benefits on bone health, vitamin D supplementation has been shown beneficial in reducing risk for many chronic diseases including autoimmune diseases, type 2 diabetes, heart disease, many cancers and infectious diseases. Vitamin deficiency has been associated with increased risk of elevated blood pressure, heart attack and stroke in studies. The relationship between vitamin D deficiency and the increased incidence of upper respiratory infections, asthma and eczema, among children, has been observed in several studies. Recent meta-analyzes showed a relationship between vitamin D administration during the early months of life and a lower incidence of type 1 diabetes later in life. Therefore, it is not surprising that Vitamin D supplementation is used to prevent and treat a wide range of diseases, and the use has increased considerably in the last decade.

The vitamin D story is unfolding quick and fast, and large amounts of scientific reports published in the last few years have made it difficult for the clinicians to keep pace with the current information on vitamin D live. Some years back, the Institute of Medicine (IOM) published a comprehensive review on this subject wherein the authors concluded that most of the scientific knowledge about the extra-skelet al benefits of vitamin $\mathrm{D}$ expenses cannot be considered as reliable. ${ }^{1}$ Hence, according to the IOM report, the need for vitamin D supplementation, beyond what is already attained through a well-balanced diet and intermittent sun exposure, is pointless for most individuals. A recent study published in The Lancet, ${ }^{2}$ funded by the Health Research

Access this article online

\begin{tabular}{|c|c|}
\hline 4 & $\begin{array}{l}\text { Website: } \\
\text { www.jmsskims.org }\end{array}$ \\
\hline apstis: & $\begin{array}{l}\text { DOI: } \\
\text { https://doi.org/10.33883/jms.v22i1.442 }\end{array}$ \\
\hline
\end{tabular}

Council of New Zealand, found that people taking Vitamin D supplements had no significant effects on their bone density. The study's authors believe that vitamin D supplementation may be a waste of time because, as per their meta-analysis, vitamin D supplementation did not prevent fractures, falls or improve bone mineral density, in whatever doses used. Therefore, it is high time to review the current evidence on the subject.

\section{Fracture risk}

A 2014 Cochrane review by Avenell A et al, ${ }^{3}$ found that there is high quality evidence that vitamin D plus calcium results in a small reduction in hip fracture risk (nine trials, 49,853 participants; RR 0.84 , 95\% confidence interval (CI) 0.74 to 0.96; P value 0.01). Overall, administration of vitamin D and calcium was associated with a statistically significant reduction in incidence of new non-vertebral fracture (eight trials, 10,380 participants, RR $0.86,95 \%$ CI 0.78 to 0.96 ). But vitamin D alone did not show statistically significant effect on hip fracture (11 trials, 27,693 participants, RR 1.12 , 95\% CI 0.98 to 1.29 ), non-vertebral fractures (12 trials, 22,930 participants, RR 1.05 , 95\% CI 0.96 to 1.14 ), vertebral fractures or deformities (six trials, 11,396 participants, RR 1.03 , 95\% CI 0.76 to 1.39 ). For any new fracture vitamin $\mathrm{D}$ alone produced no statistically significant reduction (15 trials, 28,271 participants, RR $1.03,95 \%$ CI 0.96 to 1.11). The lancet 2018 review by Boll and et $\mathrm{al}^{2}$ also from the authors of the Cochrane review, gives the same conclusions about the supplementation of vitamin $\mathrm{D}$ alone for bone health. Here they have found that in pooled analyses, vitamin D had no effect on total fracture (36 trials; $\mathrm{n}=44$ 790, relative risk $1 \cdot 00,95 \%$ CI $0 \cdot 931 \cdot 07$ ), hip fracture (20 trials; $n=36655,1 \cdot 11,0 \cdot 971 \cdot 26)$, or falls (37 trials; $n=34144,0.97,0.931 \cdot 02$ ). The results were

How to cite this article: Masoodi SR. Vitamin D supplementation Is it the time to stop wasting money on vitamin D?.jms [Internet]. 2019Mar.29 [cited 2019Apr.6];22(1). Available from: http://www.jmsskims.org/ index.php/jms/article/view/442

Received: 29-03-2019 Accepted: 29-03-2019 
Masoodi SR; Vitamin D supplementation. Is it the time to stop wasting money on vitamin D?

similar irrespective of the dose of vitamin D used (less than or more than $800 \mathrm{IU} /$ day) and randomized controlled trials that achieved higher 25OHD concentrations did not have different results. Also, they recommend based on trial sequential analyses that further similar trials are unlikely to alter the conclusions of this recent systematic review and hence not to be pursued or encouraged. They also conclude that trials of vitamin D supplementation in individuals with marked vitamin D deficiency, who are not at risk of osteomalacia, might produce different results, but require a strong scientific rationale before being undertaken, given the absence of effects of vitamin D seen in existing trials. In the review, the authors found that no new trials assessing the effect of vitamin D plus calcium supplementation on fracture risk were available after their previous review in 2014. ${ }^{3}$ Hence their own previous conclusions regarding the benefit of vitamin $\mathrm{D}$ plus calcium on fracture risk still holds. The USPSTF 2018 recommendations published in JAMA in 2018 , also found no benefit in supplementing vitamin D less than $400 \mathrm{IU}$ and calcium less than $1000 \mathrm{mg}$ daily for fracture prevention. ${ }^{4}$ These recommendations specifically exclude subjects with documented vitamin D deficiency i.e. below $25 \mathrm{nmol} / \mathrm{L}(10 \mathrm{ng} / \mathrm{mL})$.

\section{Cancer and cardiovascular risk}

The recent NEJM article by JE Manson et al, from Boston, concluded that supplementation with 2000 IU vitamin D daily did not result in a lower incidence of invasive cancer or cardiovascular events than placebo. A total of 25,871 participants were followed for a median 5.3 years, 793 in the vitamin D group and 824 in the placebo group developed cancer (hazard ratio, $0.96 ; 95 \% \mathrm{CI}, 0.88$ to $1.06 ; \mathrm{P}=0.47$ ). No significant differences between the two groups were observed with regard to the incidence of breast, prostate, or colorectal cancer. A major cardiovascular event occurred in 396 participants in the vitamin D group and 409 in the placebo group (hazard ratio, $0.97 ; 95 \% \mathrm{CI}, 0.85$ to $1.12 ; \mathrm{P}=$ 0.69). All-cause mortality was also not significantly different in either group. The effects were not different in any baseline vitamin D status groups. But reassuringly, adverse effects like hypercalcemia or kidney stones were also not higher in the vitamin $\mathrm{D}$ group. Meta analyses prior to this large study ${ }^{6}$ had found no decrease in cancer incidence, but reduced mortality from cancer with vitamin D supplementation. But this trial negates even that benefit with vitamin D supplementation. But as the authors declare themselves, the power of this trial to assess site specific cancer risk was limited considering the higher risk reduction effects of vitamin $\mathrm{D}$ in previous trials ${ }^{7.8}$ on colon cancer specifically. Also the trial duration needs to be even more than that of this trial to ascertain the effects fully. This is also true in case of the effect of intervention on cardiovascular outcomes which also needs an extended follow up. But this trial authors finally suggest that the results may be different in patients with very low vitamin $\mathrm{D}$ levels (less than $20 \mathrm{ng} / \mathrm{mL}$ ) but a long duration trial with a control group maintained at such low levels of vitamin D is not ethically acceptable and hence unlikely to be designed or executed.

\section{Summary}

Vitamin D supplementation alone is unlikely to be of any benefit in improving musculoskel et al health (falls, fracture or BMD improvement). Calcium and vitamin D cosupplementation is marginally useful in preventing fracture but needs further trials. Vitamin D at the dose of $2000 \mathrm{IU}$ daily is not helpful in reducing the incidence of cancer, cardiovascular disease or mortality. The use of vitamin $\mathrm{D}$ in reducing disease specific mortality in colon cancer needs further study. These conclusions are not valid in people with osteomalacia or documented vitamin D deficiency (variously defined as less than $10-20 \mathrm{ng} / \mathrm{mL}$ ). Therefore, on the strength of existing evidence, there seems little justification for more studies on vitamin D supplementation looking at musculoskel et al outcomes.

\section{REFERENCES}

1. Ross AC, Taylor CL, Yaktine AL, Del Valle HB, eds.; Institute of Medicine (U.S.) Committee. Dietary reference intakes for calcium and vitamin D. Washington DC: National Academies Press, 2011.

2. Bolland MJ, Grey A, Avenell A. Effects of vitamin D supplementation on musculoskel et al health: a systematic review, meta-analysis, and trial sequential analysis. lancet Diabetes Endocrinol 2018;6(11):84758.

3. Avenell A, Mak JC, O'Connell D. Vitamin D and vitamin $\mathrm{D}$ analogues for preventing fractures in postmenopausal women and older men. Cochrane Database Syst Rev 2014;(4).

4. Grossman DC, Curry SJ, Owens DK, et al. Vitamin D, 
Masoodi SR; Vitamin D supplementation. Is it the time to stop wasting money on vitamin D?

Calcium, or Combined Supplementation for the Primary Prevention of Fractures in CommunityDwelling Adults. JAMA 2018;319(15):1592.

5. Manson JE, Cook NR, Lee I-M, et al. Vitamin D Supplements and Prevention of Cancer and Cardiovascular Disease. N Engl J Med 2019;380(1):3344.

6. Keum N, Giovannucci E. Vitamin D supplements and cancer incidence and mortality: a meta-analysis. Br J Cancer 2014;111(5):97680.

7. McCullough ML, Zoltick ES, Weinstein SJ, et al. Circulating Vitamin D and Colorectal Cancer Risk:
An International Pooling Project of 17 Cohorts. JNCI J Natl Cancer Inst 2019;111(2):15869.

8. Wu K, Willett WC, Fuchs CS, Colditz GA, Giovannucci EL. Calcium intake and risk of colon cancer in women and men. J Natl Cancer Inst 2002;94(6):43746.

\section{Shariq Rashid Masoodi \\ MD, DM, FACP, FRCP}

Professor, Department of Endocrinology, SKIMS 